\title{
Resistance to bond degradation between dual-cure resin cements and pre-treated sintered CAD-CAM dental ceramics
}

\author{
Raquel Osorio ${ }^{1}$, Raquel Castillo-de Oyagüe ${ }^{2}$, Francesca Monticelli ${ }^{3}$, Estrella Osorio ${ }^{1}$, Manuel Toledano ${ }^{1}$ \\ ${ }^{1}$ Professor. Department of Dental Materials, School of Dentistry. University of Granada (UGR), Granada, Spain \\ ${ }^{2}$ Associate Professor. Department of Buccofacial Prostheses, Faculty of Odontology. Complutense University of Madrid (UCM), \\ Madrid, Spain \\ ${ }^{3}$ Tenured Professor. Department of Surgery, Faculty of Sport and Health Sciences. University of Zaragoza, Campus de Huesca, \\ Huesca, Spain
}

Correspondence:

Department of Buccofacial Prostheses

Faculty of Odontology

Complutense University of Madrid, UCM

Pza. Ramón y Cajal, s/n

E-28040, Madrid, Spain

raquel.castillo@odon.ucm.es

Osorio R, Castillo-de Oyagüe R, Monticelli F, Osorio E, Toledano M. Resistance to bond degradation between dual-cure resin cements and pre-treated sintered CAD-CAM dental ceramics. Med Oral Patol Oral Cir Bucal. 2012 Jul 1;17 (4):e669-77.

http://www.medicinaoral.com/medoralfree01/v17i4/medoralv17i4p669.pdf

Received: 21/07/2011 Accepted: 03/08/2011

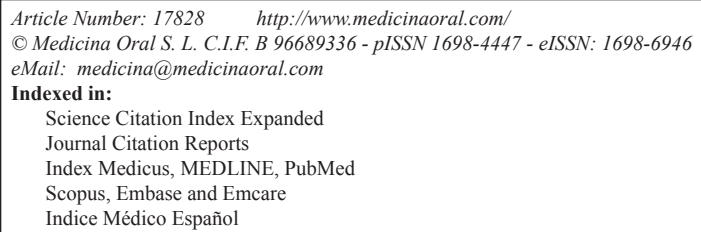

\begin{abstract}
Objective: To evaluate the bond stability of resin cements when luted to glass-reinforced alumina and zirconia $\mathrm{CAD} / \mathrm{CAM}$ dental ceramics.

Study design: Eighteen glass-infiltrated alumina and eighteen densely sintered zirconia blocks were randomly conditioned as follows: Group 1: No treatment; Group 2: Sandblasting (125 $\mu \mathrm{m} \mathrm{Al}_{2} \mathrm{O}_{3}$-particles); and Group 3: Silica-coating ( $50 \mu \mathrm{m}$ silica-modified $\mathrm{Al}_{2} \mathrm{O}_{3}$-particles). Composite samples were randomly bonded to the pretreated ceramic surfaces using different resin cements: Subgroup 1: Clearfil Esthetic Cement (CEC); Subgroup 2: RelyX Unicem (RXU); and Subgroup 3: Calibra (CAL). After $24 \mathrm{~h}$, bonded specimens were cut into $1 \pm 0.1 \mathrm{~mm}^{2}$ sticks. One-half of the beams were tested for microtensile bond strength (MTBS). The remaining one-half was immersed in $10 \% \mathrm{NaOCl}$ aqueous solution $\left(\mathrm{NaOCl}_{\text {aq }}\right)$ for $5 \mathrm{~h}$ before testing. The fracture pattern and morphology of the debonded surfaces were assessed with a field emission gun scanning electron microscope (FEG-SEM). A multiple ANOVA was conducted to analyze the contributions of ceramic composition, surface treatment, resin cement type, and chemical challenging to MTBS. The Tukey test was run for multiple comparisons $(\mathrm{p}<0.05)$.

Results: After 24 h, CEC luted to pre-treated zirconia achieved the highest MTBS. Using RXU, alumina and zirconia registered comparable MTBS. CAL failed prematurely, except when luted to sandblasted zirconia. After $\mathrm{NaOCl}_{\text {aq }}$ storage, CEC significantly lowered MTBS when luted to zirconia or alumina. RXU decreased MTBS only when bonded to silica-coated alumina. CAL recorded $100 \%$ of pre-testing failures. Micromorphological alterations were evident after $\mathrm{NaOCl}_{\text {aq }}$ immersion.
\end{abstract}


Conclusions: Resin-ceramic interfacial longevity depended on cement selection rather than on surface pre-treatments. The MDP-containing and the self-adhesive resin cements were both suitable for luting CAD/CAM ceramics. Despite both cements being prone to degradation, RXU luted to zirconia or untreated or sandblasted alumina showed the most stable interfaces. CAL experimented spontaneous debonding in all tested groups.

Key words: CAD/CAM ceramic, alumina, zirconia, resin cement, surface pre-treatment, sandblasting, silica-coating, chemical aging, bond degradation, microtensile bond strength.

\section{Introduction}

Densely sintered zirconia and glass-infiltrated alumina have expanded clinical indications for all-ceramic tooth- and implant-supported fixed dental prostheses (FDPs) $(1,2)$.

Even when CAD/CAM-based ceramic restorations can be fixed with conventional cements such as zinc-phosphate or resin-modified glass-ionomer, adhesive cementation has been recommended for improving the clinical retention and marginal fit (1).

Nevertheless, searching for a suitable luting strategy to achieve durable bonds between resin cements and high-strength ceramic cores is still a matter of concern $(3,4)$. Alternative porcelain surface treatments such as sandblasting or silica-coating have been suggested, as neither hydrofluoric acid etching nor silanization result in a satisfactory bond to alumina or zirconia due to the absence of a silicon oxide phase in their composition $(4,5)$. However, the influence of conditioning methods on resin bond strength and durability has not been accurately quantified for $\mathrm{CAD} / \mathrm{CAM}$ dental ceramics $(6,7)$. New dual-cure resin cements, such as the phosphate monomer-containing Clearfil Esthetic Cement and the self-adhesive RelyX Unicem have widely been indicated for luting sintered ceramic cores $(4,6,8)$. However, little information is available in the literature about the longevity of these bonds $(8,9)$; and many factors, e.g., ceramic wettability, porcelain surface roughness or the bonding agents' composition and performance may affect the quality of the resin cement/ceramic adhesion (10).

Furthermore, acidic compounds in dentinal fluids, salivary enzymes, and proteolytic residues produced by oral bacteria may hamper the stability of adhesive interfaces $(10,11)$, and have recently been considered as potential sources of chemical bond degradation $(10,12)$. Besides, bonded ceramic restorations promote higher crevicular fluid accumulation (with bacterial products and host-derived factors) than do dental tissues $(13,14)$. Based on the presence of sodium azide in artificial saliva, immersion in a sodium hypochlorite aqueous solution $\left(\mathrm{NaOCl}_{\mathrm{aq}}\right)$ has been proposed as a suitable and less time-consuming aging technique $(15,16)$ that may reproduce in just a few hours the long-term hydrolytic effect of the mentioned bond biodegradators present in saliva $(12,17-19)$. Thus, $\mathrm{NaOCl}$ solutions have been des- cribed as potent deproteinizing and biological oxidants with the capability of accelerating natural bond deterioration (18). Such storage medium has been considered to have similar efficacy and lower variability than water aging or thermocycling (16).

Because the aim of this study was to test the resistance to chemical degradation of different dual-cure resin cements luted to pre-treated alumina and zirconia ceramic surfaces, immersion of bonded specimens in $\mathrm{NaOCl}_{\mathrm{ac}}$ was performed. The null hypothesis tested was that neither ceramic composition, nor conditioning method, nor resin cement type influence the bond stability of resin cement/ceramic interfaces.

\section{Material and Methods}

\section{-Experimental design}

Eighteen cubic-shaped (edge $=19.5 \mathrm{~mm}$ ) sintered and glass-infiltrated (15 vol \% quartz glass) blocks of alumina (batch no. 7803, Al Cubes for Cerec, Vita Zahnfabrik; Bad Säckingen, Germany) and eighteen cylindershaped $(\varnothing 19.5 \mathrm{~mm} \times 5.25 \mathrm{~mm}$ high) sintered zirconia blanks (batch no. 18004627, Cercon Zirconia, Dentsply; Konstanz, Germany) were selected for the study. CADCAM aluminum and zirconium oxide ceramic blocks were randomly divided into three groups $(\mathrm{n}=6$ for each ceramic type) according to the different pre-treatments carried out: Group 1: No surface treatment; Group 2: Sandblasting using $125 \mu \mathrm{m}$ aluminum-oxide $\left(\mathrm{Al}_{2} \mathrm{O}_{3}\right)$ powder (Supradental; Madrid, Spain) applied perpendicularly to the ceramic surface for $10 \mathrm{~s}$ at a working distance of $5 \mathrm{~mm}$ under a pressure of $75 \pm 10 \mathrm{psi}$; and Group 3: Tribochemical silica-coating with $50 \mu \mathrm{m}$ $\mathrm{Al}_{2} \mathrm{O}_{3}$-particles modified by silica oxide (Supradental; Madrid, Spain). Thirty-six composite specimens (height $=4 \mathrm{~mm}$ ) were made by layering $2 \mathrm{~mm}$-thick increments of a microhybrid composite (batch no. J27435, Tetric Evo Ceram, Ivoclar-Vivadent; Schäan, Liechtenstein) using a square silicon mold for the alumina cubes and a rounded one for the zirconia ceramic cylinders. Each composite film was condensed with a clean plastic filling instrument to avoid contamination, and light-cured for $40 \mathrm{~s}$ at $600 \mathrm{mmW} / \mathrm{cm}^{2}$ (BluePhase, Ivoclar-Vivadent; Schäan, Liechtenstein). The last increment was compressed using a glass microscope slide in order to obtain a flat surface. After removing the specimens from the 
mold, the portions that were previously in contact with the silicone pattern were irradiated for an extra $40 \mathrm{~s}$.

\section{-Luting procedure}

Composite samples were randomly bonded to the treated ceramic surfaces using different resin cements: Subgroup 1 (CEC) used an MDP-containing resin cement: Clearfil Esthetic Cement (batch no. 00002A/0001AB, Kuraray Medical; Okayama, Japan); Subgroup 2 (RXU) used a self-adhesive resin agent: RelyX Unicem (batch no. 245776, 3M ESPE; Seefeld, Germany); and Subgroup 3 (CAL) used a conventional Bis-GMA resin cement: Calibra (batch no. 060112 (base) / 051151 (catalyst), DeTrey Dentsply; Konstanz, Germany). All materials were handled following the manufacturer's instructions at room temperature (RT) of $23.0^{\circ} \mathrm{C} \pm 1.0^{\circ} \mathrm{C}$. The chemical composition and application mode of the cements tested are detailed in table 1.
The ceramic-to-composite luting procedures were carried out by means of a customized metallic tool that produced a constant seating pressure of $1 \mathrm{~kg}(1,249 \mathrm{MPa})$. The compressive force was applied for 5 min, leaving the resin cement to set in the self-curing modality. Finally, the specimens were photo-activated for $40 \mathrm{~s}$ on each side of the blocks (BluePhase: $600 \mathrm{mmW} / \mathrm{cm}^{2}$ ) to ensure optimal polymerization. Bonded specimens were stored in distilled water for $24 \mathrm{~h}$ at $37^{\circ} \mathrm{C}$.

-Microtensile bond strength test

After $24 \mathrm{~h}$ of water storage, all samples were vertically sectioned under water cooling into $1 \pm 0.1 \mathrm{~mm}^{2}$ sticks using a slow-speed diamond saw (Accutom 50, Struers $\mathrm{GmbH}$; Copenhagen, Denmark) according to the "nontrimming" method of the microtensile test. One-half of the specimens from each experimental subgroup were tested for microtensile bond strength (MTBS). The

Table 1. Chemical composition and application mode of the resin cements tested in the study.

\begin{tabular}{|c|c|c|}
\hline \multicolumn{3}{|c|}{ CHEMICAL COMPOSITION AND APPLICATION MODE OF THE RESIN CEMENTS TESTED IN THE STUDY } \\
\hline Cement type & $\begin{array}{c}\text { Main components } \\
\text { (according to manufacturers) }\end{array}$ & Mode/steps of application \\
\hline $\begin{array}{l}\text { Clearfil Esthetic } \\
\text { Cement } \\
\text { batch no. } 00002 \mathrm{~A} / \\
\text { 0001AB }\end{array}$ & 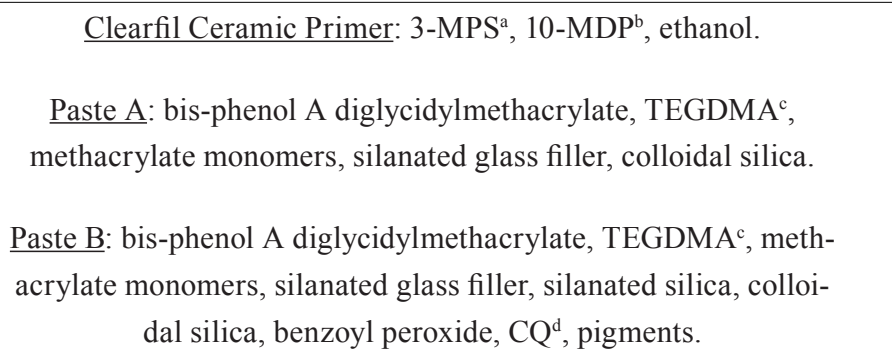 & $\begin{array}{l}\text { Apply the primer on the } \\
\text { ceramic surface and air-dry. } \\
\text { Mix the cement pastes. } \\
\text { Apply the mixture on the } \\
\text { ceramic surface. } \\
\text { Self-cure ( } 5 \text { min) and photo- } \\
\text { cure }(40 \text { s). }\end{array}$ \\
\hline $\begin{array}{l}\text { RelyX Unicem } \\
\text { batch no. } 245776\end{array}$ & $\begin{array}{l}\text { Powder: glass fillers, silica, calcium hydroxide, self-curing initia- } \\
\text { tors, pigments, light-curing initiators. } \\
\text { Liquid: methacrylated phosphoric esters, dimethacrylates, aceta- } \\
\text { te, stabilizers, self-curing initiators, light-curing initiators. }\end{array}$ & $\begin{array}{l}\text { Mix the cement. } \\
\text { Apply the mixture on the } \\
\text { ceramic surface, self-cure }(5 \\
\text { min) and photocure }(40 \mathrm{~s}) \text {. }\end{array}$ \\
\hline $\begin{array}{l}\text { Calibra } \\
\text { batch no. } \\
060112 \text { (base) } \\
051151 \text { (catalyst) }\end{array}$ & $\begin{array}{l}\text { Calibra silane coupling agent: ethyl alcohol, acetone, benzene, } \\
\text { 3-MPS }{ }^{\mathrm{a}} \text {. } \\
\text { Base: barium boron fluoroalumino silicate glass, bis-phenol A } \\
\text { diglycidyl-methacrylate, polymerizable dimethacrylate resin, hydro- } \\
\text { phobic amorphous fumed silica, titanium dioxide, dl-CQ }{ }^{\text {. }} \\
\text { Catalyst: barium boron fluoroalumino silicate glass, bis-phenol } \\
\text { A diglycidylmethacrylate, polymerizable dimethacrylate resin, } \\
\text { hydrophobic amorphous fumed silica, titanium dioxide, benzoyl } \\
\text { peroxide. }\end{array}$ & $\begin{array}{l}\text { Apply the silane on the ce- } \\
\text { ramic surface. } \\
\text { Gently air-dry after } 5 \mathrm{~s} \text {. } \\
\text { Light-cure for } 20 \mathrm{~s} \text {. } \\
\text { Mix base and catalyst (1:1). } \\
\text { Apply the mixed cement on } \\
\text { the ceramic surface. Self- } \\
\text { cure (5 min). } \\
\text { Photocure }(40 \mathrm{~s}) .\end{array}$ \\
\hline
\end{tabular}

(a) 3-MPS: 3-methacryloxypropyl trimethoxysilane; (b) 10-MDP: 10-methacryloxydecyl dihydrogen phosphate; (c) TEGDMA: triethylene glycol-dimethacrylate; (d) CQ: camphoroquinone. 
remaining one-half were stored in a $10 \%$ sodium hypochlorite aqueous solution $\left(\mathrm{NaOCl}_{\mathrm{aq}}\right)$ for $5 \mathrm{~h}$. Beams were then retrieved from the challenging medium and tested in microtension.

Twenty microtensile sticks were obtained per subgroup. Each stick was attached with cyanoacrilate adhesive ( $\mathrm{Za}-$ pit, Dental Ventures of America; Corona, CA, USA) to the flat grip of a Bencor Multi-T testing assembly (Danville Engineering; San Ramon, CA, USA) and loaded in tension with a bench-top universal testing machine (Instron Model 4411, Instron; Canton, MA, USA) at a cross-head speed of $0.5 \mathrm{~mm} / \mathrm{min}$ until failure. The detached area of the ceramic beams was measured with a pair of digital callipers. Microtensile bond strength (MTBS) values were calculated in MPa.

Failure modes were evaluated by a single operator under an optical microscope (BH-2 Olympus; Tokyo, Japan) at 70× magnifications, and classified as adhesive (at the cement/ ceramic interface), cohesive (within the resin cement), or mixed (with both adhesive and cohesive phases).

-Statistical analysis

Normal data distribution was confirmed by the Kolmogorov-Smirnov test, and homogeneity of variances was verified according to the Levene's test. A multiple ANOVA was conducted to analyze the contributions of ceramic composition, surface treatment, resin cement type, chemical challenging, as well as the interaction of these factors to MTBS. The Tukey's test was run to make post-hoc multiple comparisons. Pre-test failures of the beams, that occurred spontaneously prior to microtensile testing, were counted as "zero bonds" (MPa $=0$ ). The statistical significance was set at $\alpha=0.05$. All data analyses were made with SPSS/PC+ v.17.0 statistical software (SPSS Inc.; Chicago, IL, USA).

-Field emission gun scanning electron microscope (FEG-SEM) evaluation

Four representative sticks from each subgroup were rinsed with $96 \%$ ethanol, mounted on metallic stubs, gold sputtered (Emitech k550×, Emitech; Ashford, UK), and evaluated by a single operator under a field emission gun scanning electron microscope (FEG-SEM: JSM-6330 F, Jeol; Tokyo, Japan) at different magnifications (from $95 \times$ to $1000 \times$ ) using an accelerating voltage of $10 \mathrm{kV}$, in order to assess the fracture pattern and the morphology of the debonded surfaces.

\section{Results}

Ceramic composition, surface treatment, resin cement type, and $\mathrm{NaOCl}_{\mathrm{aq}}$ immersion significantly affected bond strengths to CAD-CAM ceramics ( $p<0.001)$. Interactions were also significant except the interaction between ceramic composition and challenging procedure $(\mathrm{p}=$ 0.558). The mean MTBS values (MPa) and the results of the post-hoc comparisons are outlined in table 2 .

Table 2. Mean (standard deviation) of microtensile bond strength ( $\mathrm{MPa}$ ) recorded in the tested groups.

\begin{tabular}{|c|c|c|c|c|c|c|c|c|c|c|c|c|}
\hline \multicolumn{13}{|c|}{ Mean (SD) of microtensile bond strength (MPa) recorded in the tested groups } \\
\hline & \multicolumn{4}{|c|}{ Clearfil Esthetic Cement } & \multicolumn{4}{|c|}{ RelyX Unicem } & \multicolumn{4}{|c|}{ Calibra } \\
\hline & \multicolumn{2}{|c|}{$\begin{array}{c}\text { Water storage } \\
24 \mathrm{~h}\end{array}$} & \multicolumn{2}{|c|}{$\begin{array}{c}\mathrm{NaOCl}_{\mathrm{aq}} \text { aging } \\
(5 \mathrm{~h})\end{array}$} & \multicolumn{2}{|c|}{$\begin{array}{c}\text { Water storage } \\
24 \mathrm{~h} \\
\end{array}$} & \multicolumn{2}{|c|}{$\begin{array}{c}\mathrm{NaOCl}_{\text {aq }} \text { aging } \\
(5 \mathrm{~h})\end{array}$} & \multicolumn{2}{|c|}{$\begin{array}{c}\text { Water storage } \\
24 \mathrm{~h} \\
\end{array}$} & \multicolumn{2}{|c|}{$\begin{array}{c}\mathrm{NaOCl}_{\mathrm{aq}} \\
\operatorname{aging}(5 \mathrm{~h})\end{array}$} \\
\hline & Alum & Zirc & Alum & Zirc & Alum & Zirc & Alum & Zirc & Alum & Zirc & Alum & Zirc \\
\hline No treatment & $\begin{array}{c}13.27 \\
(2.43)^{\mathrm{bc}}\end{array}$ & $\begin{array}{c}17.04 \\
(5.70)^{b^{*}}\end{array}$ & $\begin{array}{c}6.47 \\
(2.06)^{\mathrm{e}}\end{array}$ & $\begin{array}{c}12.60 \\
(2.24)^{\mathrm{cd}}\end{array}$ & $\begin{array}{c}11.84 \\
(1.32)^{\mathrm{cd}}\end{array}$ & $\begin{array}{c}8.73 \\
(2.50)^{\mathrm{de}}\end{array}$ & $\begin{array}{c}9.36 \\
(1.98)^{\mathrm{cde}}\end{array}$ & $\begin{array}{c}6.77 \\
(2.25)^{\mathrm{e}^{*}}\end{array}$ & - & - & - & - \\
\hline Sandblasting & $\begin{array}{c}13.42 \\
(1.50)^{\mathrm{bc}}\end{array}$ & $\begin{array}{c}18.63 \\
(6.44)^{\mathrm{a}^{*}}\end{array}$ & $\begin{array}{c}7.13 \\
(1.75)^{\mathrm{e}}\end{array}$ & $\begin{array}{c}11.34 \\
(2.31)^{\mathrm{cd}}\end{array}$ & $\begin{array}{c}12.57 \\
(1.14)^{\mathrm{cd}}\end{array}$ & $\begin{array}{c}11.44 \\
(2.46)^{\mathrm{cd}}\end{array}$ & $\begin{array}{c}8.06 \\
(2.93)^{\mathrm{de}} \\
\end{array}$ & $\begin{array}{c}10.66 \\
(2.13)^{\text {cde }}\end{array}$ & - & $\begin{array}{c}10.84 \\
(2.40)^{\text {cde }}\end{array}$ & - & - \\
\hline Silica-coating & $\begin{array}{c}11.60 \\
(2.09)^{\mathrm{cd}}\end{array}$ & $\begin{array}{c}18.19 \\
(5.51)^{\mathrm{a}^{*}}\end{array}$ & $\begin{array}{c}7.08 \\
(2.52)^{\mathrm{e}}\end{array}$ & $\begin{array}{c}13.64 \\
(2.50)^{\mathrm{bc}}\end{array}$ & $\begin{array}{c}11.65 \\
(1.64)^{\mathrm{cd}}\end{array}$ & $\begin{array}{c}8.88 \\
(2.21)^{\text {de }}\end{array}$ & $\begin{array}{c}6.60 \\
(1.95)^{\mathrm{e}}\end{array}$ & $\begin{array}{c}12.09 \\
(2.32)^{\mathrm{cd}^{*}}\end{array}$ & - & - & - & - \\
\hline
\end{tabular}

Alum $=$ alumina; Zirc $=$ zirconia

Equal superscript letters in rows indicate no significant differences $(\mathrm{p}>0.05)$.

* indicates significant differences between groups in the same column $(\mathrm{p}<0.05)$.

-: No bond strength was measured due to pre-testing failure of all specimens. 
After $24 \mathrm{~h}$ of water immersion, CEC bonded to pretreated zirconia achieved the highest MTBS. CEC luted to zirconia showed significantly higher MTBS than that of RXU bonded to alumina or zirconia regardless of the surface treatment. Despite the conditioning method, both ceramics registered comparable MTBS when RXU was used; while CEC and RXU attained comparable results when luted to alumina. CAL samples failed prematurely excluding air-abraded zirconia surfaces, which showed comparable MTBS values to those of CEC luted to alumina, and RXU bonded to alumina or zirconia.

After $\mathrm{NaOCl}_{\text {aq }}$ storage, CEC significantly decreased MTBS in all subgroups. RXU lowered MTBS only when luted to silica-coated alumina. After challenging, CEC and RXU resulted in comparable MTBS when applied to sandblasted or silica-coated zirconia; whereas untreated zirconia bonded to $\mathrm{CEC}$ resulted in higher MTBS than when luted to RXU. CEC and RXU bonded to alumina showed similar MTBS values after aging. Adhesion of sandblasted zirconia surfaces luted with CAL fell after $\mathrm{NaOCl}_{\text {aq }}$ immersion, so that CAL recorded $100 \%$ of pre-testing failures.

Table 3 summarizes the failure mode distribution. At 24 $\mathrm{h}$, the main failure type was mixed in all tested groups excepting zirconia beams luted with RXU, which mostly failed adhesively. Low percentages of cohesive fractures were only detected when CEC was bonded to untreated zirconia at $24 \mathrm{~h}$. A complete detachment of CAL from the porcelain surface frequently occurred irrespective of the conditioning method. After challenging, adhesive failures augmented in all groups, with the exception of silica-coated zirconia sticks luted with RXU.

Table 3. Percentage distribution (\%) of failure mode registered in the experimental groups.

\begin{tabular}{|c|c|c|c|c|c|c|c|c|c|c|c|}
\hline \multicolumn{12}{|c|}{ Percentage distribution (\%) of failure mode } \\
\hline \multirow{2}{*}{$\begin{array}{l}\text { Ceramic } \\
\text { type }\end{array}$} & \multirow{2}{*}{$\begin{array}{l}\text { Surface } \\
\text { treatment }\end{array}$} & \multirow{2}{*}{$\begin{array}{c}\text { Testing } \\
\text { conditions }\end{array}$} & \multicolumn{3}{|c|}{ Clearfil Esthetic Cement } & \multicolumn{3}{|c|}{ RelyX Unicem } & \multicolumn{3}{|c|}{ Calibra } \\
\hline & & & $\mathbf{A}$ & C & $\mathbf{M}$ & $\mathbf{A}$ & C & M & $\mathbf{A}$ & C & M \\
\hline \multirow[t]{6}{*}{ Alumina } & \multirow[t]{2}{*}{ No treatment } & Water -24 h & 42 & - & 58 & 45 & - & 55 & 100 & - & - \\
\hline & & $\mathrm{NaOCl}_{\mathrm{aq}}-5 \mathrm{~h}$ & 76 & - & 24 & 79 & - & 21 & 100 & - & - \\
\hline & \multirow[t]{2}{*}{ Sandblasting } & Water -24 h & 38 & - & 62 & 43 & - & 57 & 100 & - & - \\
\hline & & $\mathrm{NaOCl}_{\mathrm{aq}}-5 \mathrm{~h}$ & 74 & - & 26 & 64 & - & 36 & 100 & - & - \\
\hline & \multirow[t]{2}{*}{ Silica-coating } & Water -24 h & 47 & - & 53 & 46 & - & 54 & 100 & - & - \\
\hline & & $\mathrm{NaOCl}_{\mathrm{aq}}-5 \mathrm{~h}$ & 75 & - & 25 & 81 & - & 19 & 100 & - & - \\
\hline \multirow[t]{6}{*}{ Zirconia } & \multirow[t]{2}{*}{ No treatment } & Water -24 h & 27 & 14 & 59 & 70 & - & 30 & 100 & - & - \\
\hline & & $\mathrm{NaOCl}_{\mathrm{aq}}-5 \mathrm{~h}$ & 42 & - & 58 & 74 & - & 26 & 100 & - & - \\
\hline & \multirow[t]{2}{*}{ Sandblasting } & Water -24 h & 32 & - & 68 & 69 & - & 31 & 72 & - & 18 \\
\hline & & $\mathrm{NaOCl}_{\mathrm{aq}}-5 \mathrm{~h}$ & 43 & - & 57 & 73 & - & 27 & 100 & - & - \\
\hline & \multirow[t]{2}{*}{ Silica-coating } & Water -24 h & 36 & - & 64 & 85 & - & 15 & 100 & - & - \\
\hline & & $\mathrm{NaOCl}_{\mathrm{aq}}-5 \mathrm{~h}$ & 47 & - & 53 & 51 & - & 49 & 100 & - & -- \\
\hline
\end{tabular}

A: Adhesive failure (between the ceramic and the resin cement). C: cohesive failure (within the resin cement). M: mixed failure (with both adhesive and cohesive phases). 
Representative FEG-SEM images are presented in figures 1 to 3. Sandblasted substrates evidenced edgeshaped micro-roughness (Fig. 1.A) whereas silica-coated beams showed a slight undulation in their surface texture with homogeneously distributed micro-irregularities (Fig. 1.B). At $24 \mathrm{~h}$, remaining cement layers mainly luted to pre-treated ceramics were observed (Figs. 2.A,B). After $\mathrm{NaOCl}_{\text {aq }}$ immersion, cement residuals of CEC (Figs. 3.A, B) and RXU (Fig. 3.C) persisted above the ceramic substrates.

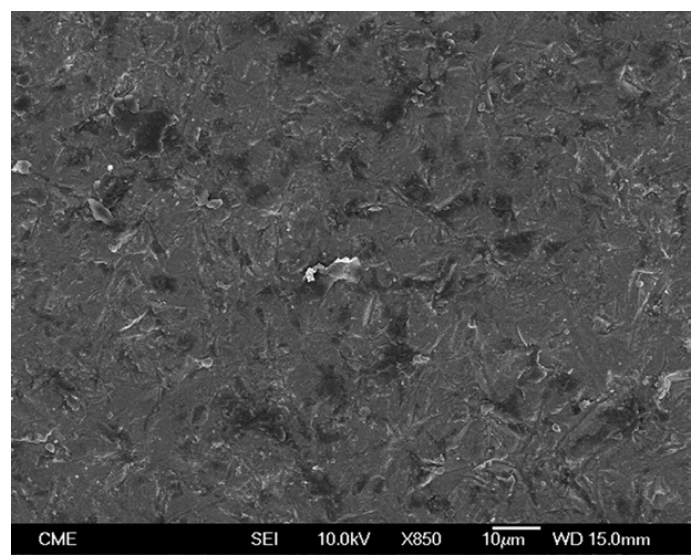

Fig. 1. FEG-SEM micrographs of pre-treated ceramics. A) Sandblasted alumina surfaces exhibited edge-shaped microroughness $(850 \times$; bar $10 \mu \mathrm{m})$.

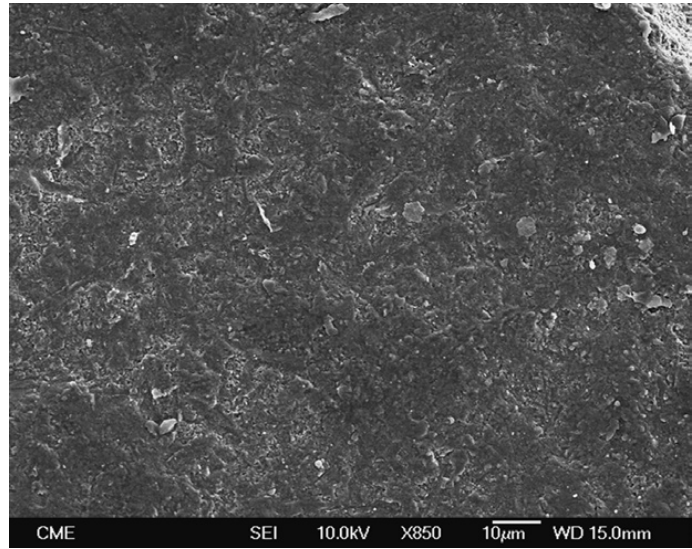

Fig. 1. B) A slight undulation in the zirconia surface texture was observed after silica-coating $(850 \times$; bar $10 \mu \mathrm{m})$.

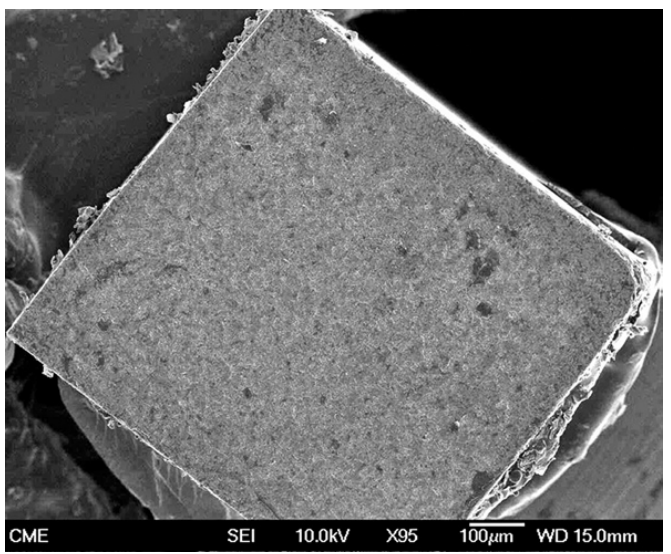

Fig. 2. FEG-SEM figures of Clearfil bonded to a sandblasted alumina surface at $24 \mathrm{~h}$. A) Cohesive failure: the entire porcelain surface was covered by a resin cement film $(95 \times$; bar $100 \mu \mathrm{m})$

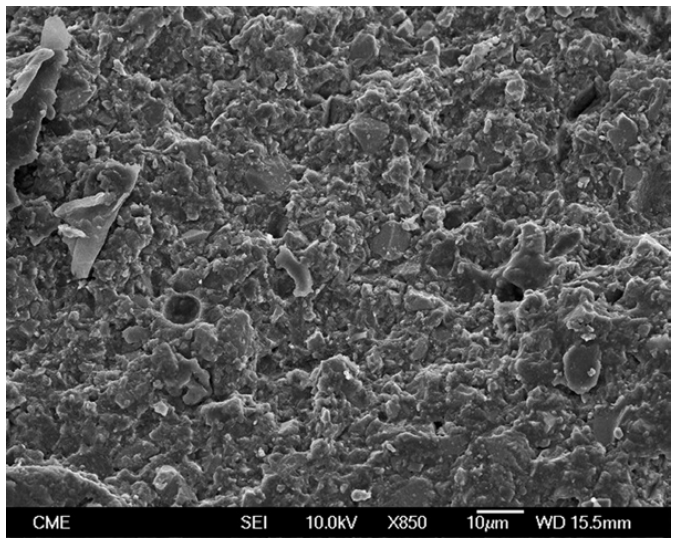

Fig. 2. B) Sparse, scattered cement porosities were detectable at higher magnification $(850 \times$; bar $10 \mu \mathrm{m})$.

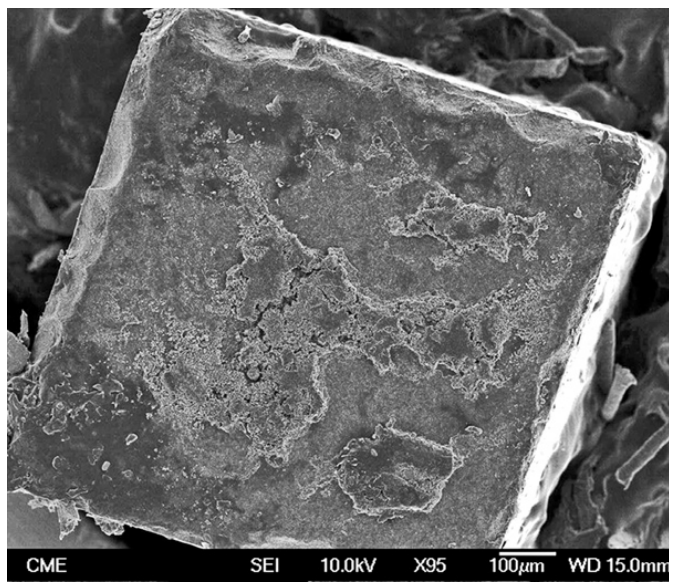

Fig. 3. FEG-SEM images of fractured beams after $\mathrm{NaO}$ $\mathrm{Cl}$ storage. A) Mixed failure of a sandblasted alumina stick bonded with Clearfil, showing cement layers with protruding filler particles $(95 \times$; bar $100 \mu \mathrm{m})$ 


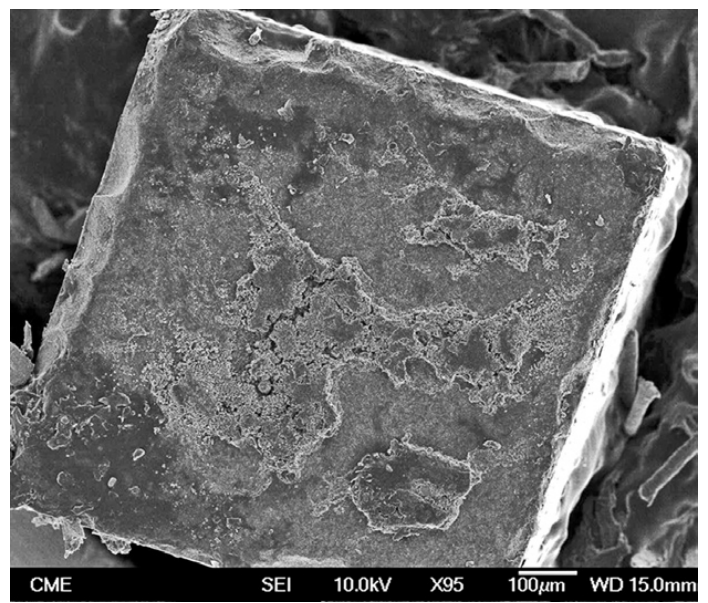

Fig. 3. B) Micro-irregularities and dissolved cement residuals were noticed at higher magnification $(850 \times$; bar $10 \mu \mathrm{m})$.

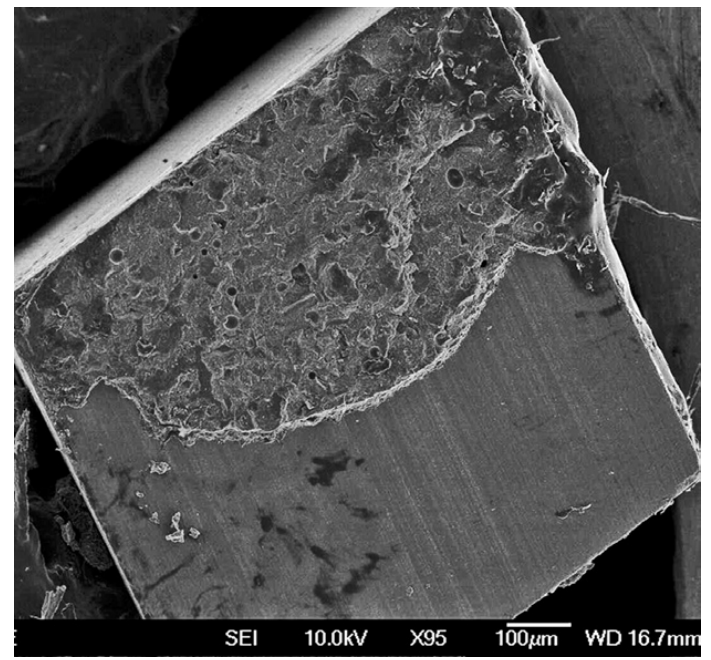

Fig. 3. C) Mixed failure of an untreated zirconia surface luted with RelyX Unicem (95×; bar $100 \mu \mathrm{m})$. Cement dissolution areas with round-shaped margins remained at the top side of the beam (cohesive phase).

\section{Discussion}

Resin cement/ceramic bonded interfaces are susceptible to degradation. Challenging these bonding sites at the laboratory is required to test the bond stability of different luting systems proposed for oxide-based ceramics (1). A microtensile test was performed, since it allows for a homogeneous distribution of stress across the adhesive interface and a sensitive evaluation of bond strength (20). The findings of the present study require rejection of the null hypothesis because ceramic composition, conditioning treatment and resin cement type influenced the bond stability at the resin cement/ ceramic interfaces.

At $24 \mathrm{~h}$ evaluation, the bond strength of CEC to pretreated zirconia reached the highest MTBS values (Ta- ble 2). Prior to CEC application, the ceramic primer was spread over the porcelain surface to improve adhesion and to protect against moisture. 3-MPS (3-methacryloxypropyl trimethoxysilane) and 10-MDP (10methacryloxy-decyl-dihydrogen phosphate) monomers present in the CEC ceramic primer composition (Table 1) optimize the surface wettability (21) and create crosslinks: (a) with the 10-MDPs dispersed in the CEC resin matrix and (b) with the hydroxyl radicals ( $\mathrm{OH}-)$ of the zirconia surfaces $(2,22)$. Consistently, the main failure type recorded in the CEC groups before challenging was mixed (Table 3 ).

In the first minute of the mixture of $\mathrm{RXU}$, the $\mathrm{pH}$ is purported to be low, less than $2 \mathrm{pH}$ units, due to the presence of multifunctional phosphoric methacrylates (Table 1). Even though this acidity seemed to promote adhesion to a glass-porcelain (IPS Empress, Ivoclar Vivadent) in a previous study (23), it remains to be ascertained whether this chemical interaction also occurs when bonded to CAD/CAM ceramics (8). In fact, RXU mostly failed adhesively at $24 \mathrm{~h}$ (Table 3 ).

CAL confirmed pre-testing failures with complete detachment from the ceramic substrates except when luting sandblasted zirconia surfaces (Tables 2 and 3) due to their rough texture $(4,8)$. An AFM analysis developed in a former investigation revealed a significant increase in the average roughness of zirconia surfaces after sandblasting (4). The lack of chemical interaction between $\mathrm{CAL}$ and the tested ceramics may be due to the absence of adhesive functional monomers in the composition of the resin cement and the silane coupling agent (24). Actually, the high content of solvents in the silane formulation may interfere with the resin polymerization, jeopardizing adhesion.

Concerning the ceramic type, glass-reinforced alumina has been reported to be rather resistant to air-abrasion and/or chemical surface reactions (25). This may explain why CEC and RXU attained comparable MTBS results despite the alumina surface pre-treatment (Table 2).

Several in vitro methods have been proposed to replicate the clinical conditions that may cause the adhesive interfaces to fail (15). Short-term immersion in $10 \%$ $\mathrm{NaOCl}_{\text {aq }}$ has previously been used to reproduce the long-term action of salivary enzymes $(10,18,19,26)$. In the current research this solution hampered the bond strength of CEC and CAL when combined with either type of ceramic and conditioning method.

After $\mathrm{NaOCl}_{\mathrm{aq}}$ storage, the structural deterioration of CEC was observable such that the resin portion seemed to be dissolved displaying protruding filler particles (Figs. 3.A, B). The use of resin cements containing adhesive phosphate monomers has been deemed the best luting strategy for both alumina (27) and zirconia (28) mainly after air-abrading the ceramic surfaces. Nevertheless, microstructural changes in the CEC resin ce- 
ment were noticeable in the comparison of FEG-SEM images taken before and after chemical aging (Figs. 2.B, 3.B, respectively).

Sandblasting is also supposed to somewhat compensate for the lack of adhesive monomers in the CAL Bis-GMA matrix $(4,8)$, but it has not contributed to bond stability (Table 2). Moreover, the 3-MPS hydrophilic monomers of the silanes used prior to CEC and CAL resin cements may have expedited interfacial sorption and hydrolytic effects thanks to the establishment of hydrogen bonds throughout the hydrophilic groups (29). This could justify the bond strength decrease of both cements after challenging.

In RXU debonded specimens, cement dissolution areas (with rounded margins) were detected by FEG-SEM after chemical aging (Fig. 3.C). The adhesive interface of RXU has been compared to that of some conventional luting agents such as silicate or zinc-phosphate cements (30). The inorganic fillers (glass silicate) may react with the acidic phosphoric ester forming a silicate gel in which glass particles are entrapped. Therefore, RXU luted to zirconia and untreated or sandblasted alumina demonstrated greater bond stability than that of the CEC and CAL subgroups. Possible differences in effective silica deposition and nanomorphological alterations produced by silica-coating on alumina and zirconia substrates deserve further investigation. Despite not being the focus of the study, it might contribute to explain why RXU decreased MTBS only when luted to silica-coated alumina. Overall, given that silanized interfaces become unstable in contact with moisture (1), RXU was the only resin cement capable of maintaining bond strength after aging, as it requires neither primer application nor silanization (Table 1).

Saliva contamination has been shown to affect the resin bond to CAD/CAM ceramics and its durability (10). Accordingly, filtrations of the NaOClaq solution at the adhesive interfaces have lead to degradation of the resin matrix of both CEC (Figs. 3.A,B) and RXU (Fig. 3.C) polymeric materials $(19,26)$, thus increasing the percentages of adhesive failures in most groups (Table 3). Nonetheless, the results of this experiment provide only an indication of the possible performance of resin cements to zirconium and aluminum oxide-based ceramics and should be reasonably extrapolated to the clinical environment. Further in vitro long-term storage studies as well as controlled clinical trials are needed to redefine these findings $(1,8)$. Within the limitations of this study, the following conclusions could be drawn: (a) resin-ceramic interfacial longevity depended on cement selection rather than on surface pre-treatments; (b) the MDP-containing (CEC) and the self-adhesive (RXU) resin cements provided adequate bond strength levels to alumina and zirconia CAD/CAM ceramics after challenging; (c) despite both cements being prone to degradation due to resin matrix dissolution, RXU luted to zirconia or untreated or sandblasted alumina showed the most stable interfaces; and (d) the conventional Bis-GMA resin cement (CAL) experimented spontaneous debonding in all tested groups regardless of the ceramic surface treatment.

\section{References}

1. Blatz MB, Sadan A, Arch GH Jr, Lang BR. In vitro evaluation of long-term bonding of Procera AllCeram alumina restorations with a modified resin luting agent. J Prosthet Dent. 2003;89:381-7.

2. Blatz MB, Sadan A, Blatz U. The effect of silica coating on the resin bond to the intaglio surface of Procera AllCeram restorations. Quintessence Int. 2003;34:542-7.

3. Burke FJ, Fleming GJ, Nathanson D, Marquis PM. Are adhesive technologies needed to support ceramics? An assessment of the current evidence. J Adhes Dent. 2002;4:7-22.

4. de Oyagüe RC, Monticelli F, Toledano M, Osorio E, Ferrari M, Osorio R. Influence of surface treatments and resin cement selection on bonding to densely-sintered zirconium-oxide ceramic. Dent Mater. 2009;25:172-9.

5. Amaral R, Ozcan M, Bottino MA, Valandro LF. Microtensile bond strength of a resin cement to glass infiltrated zirconia-reinforced ceramic: the effect of surface conditioning. Dent Mater. 2006;22:283-90.

6. Kumbuloglu O, Lassila LV, User A, Vallittu PK. Bonding of resin composite luting cements to zirconium oxide by two air-particle abrasion methods. Oper Dent. 2006;31:248-55.

7. Valandro LF, Ozcan M, Amaral R, Leite FP, Bottino MA. Microtensile bond strength of a resin cement to silica-coated and silanized In-Ceram Zirconia before and after aging. Int J Prosthodont. 2007;20:70-2.

8. Oyagüe RC, Monticelli F, Toledano M, Osorio E, Ferrari M, Osorio R. Effect of water aging on microtensile bond strength of dual-cured resin cements to pre-treated sintered zirconium-oxide ceramics. Dent Mater. 2009;25:392-9.

9. Osório AB, Camacho GB, Demarco FF, Powers JM. Microleakage in full-crown all-ceramic restorations: influence of internal surface treatment, silane application, alumina system, and substrate. Int J Prosthodont. 2007;20:123-4.

10. Yang B, Lange-Jansen HC, Scharnberg M, Wolfart S, Ludwig $\mathrm{K}$, Adelung $\mathrm{R}$, et al. Influence of saliva contamination on zirconia ceramic bonding. Dent Mater. 2008;24:508-13.

11. De Munck J, Braem M, Wevers M, Yoshida Y, Inoue S, Suzuki K, et al. Micro-rotary fatigue of tooth-biomaterial interfaces. Biomaterials. 2005;26:1145-53.

12. Monticelli F, Osorio R, Pisani-Proença J, Toledano M. Resistance to degradation of resin-dentin bonds using a one-step HEMA-free adhesive. J Dent. 2007;35:181-6.

13. Konradsson K, Claesson R, van Dijken JW. Dental biofilm, gingivitis and interleukin-1 adjacent to approximal sites of a bonded ceramic. J Clin Periodontol. 2007;34:1062-7.

14. Marsh PD. Dental plaque as a microbial biofilm. Caries Res. 2004;38:204-11.

15. Amaral FL, Colucci V, Palma-Dibb RG, Corona SA. Assessment of in vitro methods used to promote adhesive interface degradation: a critical review. J Esthet Restor Dent. 2007;19:340-53.

16. Saboia VP, Silva FC, Nato F, Mazzoni A, Cadenaro M, Mazzotti $\mathrm{G}$, et al. Analysis of differential artificial ageing of the adhesive interface produced by a two-step etch-and-rinse adhesive. Eur J Oral Sci. 2009; 117:618-24.

17. Daumer KM, Khan AU, Steinbeck MJ. Chlorination of pyridinium compounds. Possible role of hypochlorite, n-chloramines, and chlorine in the oxidation of pyridinoline cross-links of articular cartilage collagen type II during acute inflammation. J Biol Chem. 2000;275:34681-92.

18. Yamauti M, Hashimoto M, Sano H, Ohno H, Carvalho RM, Kaga $\mathrm{M}$,et al. Degradation of resin-dentin bonds using $\mathrm{NaOCl}$ storage. Dent Mater. 2003;19:399-405. 
19. Yoshida E, Hashimoto M, Hori M, Kaga M, Sano H, Oguchi H. Deproteinizing effects on resin-tooth bond structures. J Biomed Mater Res B Appl Biomater. 2004;68:29-35.

20. Betamar N, Cardew G, Van Noort R. Influence of specimen designs on the microtensile bond strength to dentin. J Adhes Dent. 2007;9:159-68

21. Lehmann F, Kern M. Durability of resin bonding to zirconia ceramic using different primers. J Adhes Dent. 2009;11:479-83.

22. Yoshida K, Tsuo Y, Atsuta M. Bonding of dual-cured resin cement to zirconia ceramic using phosphate acid ester monomer and zirconate coupler. J Biomed Mater Res B Appl Biomater. 2006;77:28-33.

23. Pisani-Proenca J, Erhardt MC, Valandro LF, Gutiérrez-Aceves G, Bolanos-Carmona MV, Del Castillo-Salmeron R, et al. Influence of ceramic surface conditioning and resin cements on microtensile bond strength to a glass ceramic. J Prosthet Dent. 2006;96:412-7.

24. Lüthy $\mathrm{H}$, Loeffel $\mathrm{O}$, Hammerle $\mathrm{CH}$. Effect of thermocycling on bond strength of luting cements to zirconia ceramic. Dent Mater. 2006;22:195-200.

25. Borges GA, Sophr AM, de Goes MF, Sobrinho LC, Chan DC. Effect of etching and airborne particle abrasion on the microstructure of different dental ceramics. J Prosthet Dent. 2003;89:479-88.

26. Ferracane JL. Hygroscopic and hydrolytic effects in dental polymer networks. Dent Mater. 2006;22:211-22.

27. Friederich R, Kern M. Resin bond strength to densely sintered alumina ceramic. Int J Prosthodont. 2002;15:333-8.

28. Wolfart M, Lehmann F, Wolfart S, Kern M. Durability of the resin bond strength to zirconia ceramic after using different surface conditioning methods. Dent Mater. 2007;23:45-50.

29. Almeida GS, Poskus LT, Guimarães JG, da Silva EM. The effect of mouthrinses on salivary sorption, solubility and surface degradation of a nanofilled and a hybrid resin composite. Oper Dent. 2010;35:105-11.

30. Monticelli F, Osorio R, Mazzitelli C, Ferrari M, Toledano M. Limited decalcification/diffusion of self-adhesive cements into dentin. J Dent Res. 2008;87:974-9.

\section{Acknowledgments}

This investigation was supported by CICYT/FEDER MAT200802347/MAT, JA-P07-CTS-2568, JA-P08-CTS-3944, and UNGR-08 $-1 \mathrm{E}-030$. 